\title{
Dropping Out of Rural China's Secondary Schools: A Mixed-methods Analysis*
}

\author{
Yaojiang Shi ${ }^{\dagger}$, Linxiu Zhang*, Yue Ma ${ }^{\S}$, Hongmei $\mathrm{Yi}_{* \star *}^{* *}$, Chengfang Liu ${ }^{\dagger \dagger}$, \\ Natalie Johnson $\$$, James Chu ${ }^{\S \S}$, Prashant Loyalka ${ }^{\star * *}$ and Scott Rozelle
}

\begin{abstract}
Students in rural China are dropping out of secondary school at troubling rates. While there is considerable quantitative research on this issue, no systematic effort has been made to assess the deeper reasons behind student decision making through a mixed-methods approach. This article seeks to explore the prevalence, correlates and potential reasons for rural dropout throughout the secondary education process. It brings together results from eight large-scale survey studies covering 24,931 rural secondary students across four provinces, as well as analysis of extensive interviews with 52 students from these same study sites. The results show that the cumulative dropout rate across all windows of secondary education may be as high as 63 per cent. Dropping out is significantly correlated with low academic performance, high opportunity cost, low socio-economic status and poor mental health. A model is developed to suggest that rural dropout is primarily driven by two mechanisms: rational cost-benefit analysis or impulsive, stress-induced decision making.
\end{abstract}

Keywords: school dropout; China; junior high school; determinants; qualitative study; mixed methods analysis

* The authors acknowledge the financial assistance of the National Natural Science Foundation of China (grant No. 71110107028 and 71033003), the International Initiative for Impact Evaluation and the Ford Foundation.

$\dagger \quad$ Center for Experimental Economics for Education, Shaanxi Normal University. Email: shiyaojiang7@gmail.com.

* Center for Chinese Agricultural Policy, Chinese Academy of Sciences. Email: lxzhang.ccap@igsnrr. ac.cn (corresponding author).

$\S \quad$ Center for Experimental Economics for Education, Shaanxi Normal University. Email: mayue2871@ 126.com.

** Center for Chinese Agricultural Policy, Chinese Academy of Sciences. Email: yihm.ccap@igsnrr.ac.cn.

t† Center for Chinese Agricultural Policy, Chinese Academy of Sciences. Email: cfliu.ccap@igsnrr.ac.cn.

Ht Rural Education Action Program, Freeman Spogli Institute, Stanford University. Email: nsydneyj@ stanford.edu.

$\S \S \quad$ Rural Education Action Program, Freeman Spogli Institute, Stanford University. Email: jchu1225@ stanford.edu.

*** Rural Education Action Program, Freeman Spogli Institute, Stanford University. Email: loyalka@ stanford.edu.

$\dagger \dagger$ Rural Education Action Program, Freeman Spogli Institute, Stanford University. Email: rozelle@ stanford.edu. 
Education has long been recognized as one of the most important inputs to a nation's economic development. ${ }^{1}$ China's history attests to the key role of education in fostering economic growth: high rates of primary and lower secondary enrolment before the 1979 economic reform have been credited as a vital contributor to China's rapid economic development over the past three decades. ${ }^{2}$ In the rest of East Asia, the countries that have shown the greatest economic growth in the second half of the 20th century underscored that growth with high rates of secondary education enrolment. ${ }^{3}$

Unfortunately, research suggests that students from China's poor, rural areas are currently receiving less secondary schooling than their urban peers. For example, well over 90 per cent of students from large cities in China attend senior high school, ${ }^{4}$ yet only half of all junior high graduates in poor, rural areas attend senior high school. ${ }^{5}$ The problem extends to every major window of the secondary schooling process: rural students are dropping out of junior high school, not matriculating into senior high school, dropping out of academic high school and dropping out of vocational high school, all at high rates. ${ }^{6}$

Given that most children in China's school system are from rural areas, the fact that they are not receiving secondary schooling at the same rate as their urban peers means that China's overall attainment in secondary education is seriously lagging and the nation is in danger of undermining its future development. Like other middle-income nations, China is increasingly shifting its emphasis from low-wage to higher-wage services and industries. ${ }^{7}$ As the economy shifts and as wages rise, individuals will need more schooling to hold the necessary skills and knowledge that these kinds of jobs require. ${ }^{8}$ In this new economy, young adults who have not finished secondary school are likely to struggle to find gainful employment in the formal sector, and many will either be forced to work in the informal economy (in which returns are low and expectations of future income increases are negligible) or be left unemployed. ${ }^{9}$ Beyond the clear detrimental effects to undereducated youths and their families, if dropout rates continue as they are today, increasing unemployment and widening inequalities could hinder economic growth and stability on a national scale. ${ }^{10}$

Although studies have used quantitative methods to understand what kinds of students are dropping out, there has been no systematic effort to investigate rural

1 Barro 1991.

2 Heckman and Yi 2012.

3 Birdsall, Ross and Sabot 1995.

4 Loyalka et al. 2014.

5 We use the term "senior high school" to refer to all upper secondary education programmes, including both academic and vocational high schools. Loyalka et al. 2013a; Liu et al. 2012.

6 We use the general term "dropout" to refer to both dropping out from school and non-matriculation into higher levels of school during the secondary schooling process. Mo et al. 2013; Yi et al. 2015; Wang, Xiaobing, et al. 2011; Yao et al. 2013.

7 International Labor Organization 2010.

8 Heckman and Yi 2012.

9 Zhang, Linxiu, et al. 2012.

10 World Bank 2005. 
China's secondary school dropout problem through mixed-methods analysis. ${ }^{11}$ Mixed-methods studies complement the empirical rigour and generalizability of quantitative research findings with the depth of interview-based case studies. ${ }^{12}$ It is only through standardized surveys administered to a large sample of students that researchers can accurately estimate the prevalence of secondary education dropout and the risk factors for a larger population. However, by its very nature, a multiple-choice survey cannot measure the complex series of value judgments and decisions that lead a student to a given educational choice. Carefully designed qualitative interviews therefore offer a unique opportunity to understand individual students' schooling decisions without boxing them into a finite list of choices that have been pre-selected by the researcher.

The purpose of our study is to gain a better understanding of the secondary school dropout rate in China and the reasons why students drop out. More specifically, we use a mixed-methods approach to explore the prevalence, correlates and potential reasons for pervasive rural dropout at the secondary school level in China. We first summarize the dropout rates at each level of the secondary education process (lower secondary school and upper secondary school) in rural China, based on results from a series of quantitative studies conducted across four Chinese provinces over the past seven years. Second, we use survey data from a subset of those studies to identify the correlates of dropping out in these schools. Finally, we use a new set of qualitative interviews to explore the reasons students give for deciding to drop out or to stay in the schooling system.

\section{Quantitative Data and Results}

\section{Sampling procedure and data collection}

Quantitative survey data were collected during eight separate efforts. The research team (made up of researchers from the Chinese Academy of Sciences, Stanford University, Northwest University and Shaanxi Normal University) collected data from 24,931 students in 262 rural junior high schools, 46 rural academic high schools, and 107 vocational high schools in four provinces - Shanxi, Shaanxi, Hebei and Zhejiang - between June 2007 and November 2013. Conducting the studies in four different provinces allows us to identify secondary school dropout prevalence and correlates across widespread regions of rural China in general and across poor areas more specifically. Over 600 million people live in rural regions of China, accounting for around half of the population. ${ }^{13}$

The data collection efforts of the eight studies are summarized in Table 1. While there were differences among the studies in the exact nature of sampling 
Table 1: Description of Studies

\begin{tabular}{|c|c|c|c|c|c|c|c|}
\hline & $\begin{array}{c}\text { Sample } \\
\text { provinces }\end{array}$ & $\begin{array}{l}\text { School level } \\
\text { surveyed }\end{array}$ & $\begin{array}{c}\text { Sample } \\
\text { characteristics }\end{array}$ & $\begin{array}{c}\text { Number of } \\
\text { sampled } \\
\text { counties }\end{array}$ & $\begin{array}{l}\text { Number of } \\
\text { sampled } \\
\text { schools }\end{array}$ & $\begin{array}{l}\text { Number of } \\
\text { sampled } \\
\text { students }\end{array}$ & Survey date \\
\hline Mo et al. 2013 & Shaanxi & 7 th grade & All students & 1 & 10 & 1,507 & 2009-2010 \\
\hline Yi et al. 2012 & $\begin{array}{l}\text { Shanxi and } \\
\text { Shaanxi }\end{array}$ & 7 th and 8 th grade & All students & 4 & 46 & 7,811 & $2009-2010$ \\
\hline $\begin{array}{l}\text { Wang, Huan, et al. } \\
\text { 2014a }\end{array}$ & Shaanxi & 7 th and 8 th grade & All students & 8 & 38 & 4,840 & 2012-2013 \\
\hline Yi et al. 2015 & $\begin{array}{c}\text { Shaanxi and } \\
\text { Hebei }\end{array}$ & 7 th and 9 th grade & $\begin{array}{l}\text { Only four poorest } \\
\text { students in each } \\
\text { class }\end{array}$ & 15 & 168 & 2,424 & 2010-2011 \\
\hline Li, Fan, et al. 2014 & $\begin{array}{l}\text { Shaanxi and } \\
\text { Hebei }\end{array}$ & 9th grade & $\begin{array}{l}\text { Only four poorest } \\
\text { students in each } \\
\text { class }\end{array}$ & 15 & 132 & 1,892 & 2012-2013 \\
\hline $\begin{array}{l}\text { Wang, Xiaobing, } \\
\text { et al. } 2011\end{array}$ & Shaanxi & Academic high school & All students & 8 & 10 & 1,177 & 2007 \\
\hline $\begin{array}{l}2013 \text { Shaanxi High } \\
\text { School Survey }\end{array}$ & Shaanxi & $\begin{array}{l}\text { Academic and } \\
\text { vocational high } \\
\text { school; 12th grade }\end{array}$ & $\begin{array}{l}\text { Only four poorest } \\
\text { students in each } \\
\text { class }\end{array}$ & 5 & 36 & 532 & 2013 \\
\hline Yao et al. 2013 & $\begin{array}{c}\text { Shaanxi and } \\
\text { Zhejiang }\end{array}$ & $\begin{array}{l}\text { Vocational high } \\
\text { school }\end{array}$ & $\begin{array}{l}\text { Only first-year } \\
\text { computer majors }\end{array}$ & - & 107 & 7,172 & $2011-2012$ \\
\hline
\end{tabular}


and data collection, all were survey-based and involved at least two rounds of investigation: a baseline survey at the beginning of the school year and an endline survey at the end of the school year. Students' dropout status was verified in all studies using two steps. First, enumerators asked the homeroom teachers to identify dropouts. Second, the survey teams also verified the status of all students that were absent during the endline survey with their classmates. Matriculation status into senior high school was also verified using two steps: homeroom teachers were surveyed to identify the students that had matriculated and our enumerators visited each senior high school to verify personally that the students were in attendance.

Beyond information on dropouts, other data were collected during the baseline and endline surveys. In each study, enumerators collected data on students' current schooling status as well as their demographic and socio-economic characteristics. Students were given a 30-minute standardized mathematics test using items from the Trends in International Mathematics and Science Study (TIMSS) so as to quantify their academic performance. In the study by Huan Wang et al., ${ }^{14}$ students were also given a 100-question mental health test, which has been shown in the literature to produce a reliable measure of general anxiety and has been widely used in China. ${ }^{15}$

A number of studies also limited their sample to "poor students." These students were identified in two steps. First, enumerators asked each homeroom teacher at the baseline survey to provide a list of the poorest students in his or her class. Second, the baseline survey for the students included a number of questions about their family assets. A monetary value was attached to each asset to produce a single ranking of family asset value in each class. ${ }^{16}$ By matching these two pieces of information together, the studies were able to identify the four poorest students in each class.

\section{The Prevalence of Dropout}

All eight studies found high dropout rates across the four major windows in secondary education (Table 2). Rates of dropout during junior high are high: 4.4 per cent to 13.3 per cent of students dropped out between the beginning of their first school year (seventh grade) and the beginning of their second school year (eighth grade). Among students who were present at the beginning of eighth grade, 9 per cent had dropped out before the beginning of ninth grade. Finally, 4.2 per cent to 8.7 per cent of students dropped out between the beginning of ninth grade and graduation. This suggests a cumulative average dropout rate across junior high ranging between 17.6 per cent and 31 per cent. These rates are six to 12 times

16 Based on the National Household Income and Expenditure Survey, published by the National Bureau of Statistics. NBS 2007. 


\section{Table 2: Dropout Rates across Windows of Secondary School}

\section{During junior high}

Mo et al. 2013

Yi et al. 2012

Wang, Huan, et al. 2014a

Yi et al. 2015

Li, Fan, et al. 2014

\section{After junior high/} before high school

Yi et al. 2015

Li, Fan, et al. 2014

\section{During senior high} school

Academic high school

Wang, Xiaobing, et al. 2011

\section{Shaanxi High School Survey}

Vocational high school

Yao et al. 2013

2013 Shaanxi High

School Survey

\section{Definition of "dropout"}

Left school and did not return during this school year

Left school and did not return during this school year

Left school and did not return during this school year

Left school and did not return during this school year

Cumulative dropout across two years

Left school and did not return during this school year

Left school and did not return during this school year

Cumulative dropout across two years

Left school and did not return during this school year

Left school and did not return during this school year

Left school and did not return during this school year

Did not enrol in senior high school*

Did not enrol in senior high school*

\section{Sampled students}

7 th grade

Poor 7 th graders

7 th grade

8 th grade

7th-8th grade

7 th grade

8th grade

7th-8th grade

Poor 7 th graders

Poor 9th graders

Poor 9th graders

Dropout rate

$(\%)$

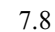

Poor students

Poor students

Left school and did not return during this school year

Left school and did not return during this school year

Cumulative dropout across three years

Cumulative dropout from autumn of 10th grade to autumn of 12 th grade

Left school and did not return during this school year

Cumulative dropout from autumn of 10th grade to autumn of 12 th grade
Poor 12th graders

3.7

Non-poor 12th

graders

Poor 10th-12th graders

Poor 10th-12th

graders

First year

computer majors

Poor 10th-12th graders

Notes:

${ }^{*}$ Academic or vocational high school; students who dropped out during junior high school are also counted as not matriculating into senior high school.

higher than the government's most recently reported (three-year cumulative) junior high dropout rate of 2.6 per cent. ${ }^{17}$

Including students who drop out during junior high school and students who finish junior high and then leave school, the largest drop in secondary education

17 Ministry of Education 2006. 
enrolment occurs prior to senior high school. Our studies show that more than half (between 51.2 per cent and 53.5 per cent) of poor rural students did not enrol in any kind of senior high school (academic or vocational). Thus, while over 90 per cent of students in large cities in China attend senior high school, our studies confirm that less than half of students in rural China are continuing their education past the junior high school level. ${ }^{18}$

Even if students enter senior high school, there is no guarantee that they will finish. Among the students that continued with their secondary education, either to academic high school or vocational high school, the dropout rate remained high. Between 4.2 per cent and 7.4 per cent of students who enrolled in academic high school dropped out before graduating. The dropout rate from vocational high schools was even higher: between 29 per cent and 32 per cent of students enrolled in vocational high schools will drop out before completing their studies.

We then estimate a cumulative dropout rate throughout the secondary education process ranging from 59 per cent (most conservative) to 63 per cent (most liberal). Specifically, if 100 students begin junior high, we can calculate the proportion of students who complete each window of secondary schooling. If we take the most liberal statistics, we can estimate that after some students drop out during junior high (roughly 31 children, or 31 per cent, drop out in junior high), a total of only 46 will enrol in senior high school (54 per cent do not matriculate, including prior dropouts). If 54 per cent of the remaining students go to academic high school and 46 per cent go to vocational schools, we can also calculate the number that will drop out during senior high. ${ }^{19}$ Specifically, 25 students will attend academic high school but only 23 will graduate (a dropout rate of 7 per cent), and 21 students will attend vocational high school but only 14 will graduate (a dropout rate of 32 per cent). In total, only 37 out of 100 rural students who begin junior high school will graduate from secondary schooling (14 from vocational school and 23 from an academic high school). By these numbers, assuming that individuals will need a high school education to get a job in the formal sector in the coming decades, less than 40 per cent of rural students are going to be prepared for China's coming higher-wage economy.

\section{The Correlates of Dropping Out}

Of the eight studies included in our dataset, four of them also specifically investigated the correlates of dropping out during different windows of the secondary education process. The objective of this work is to gain a better understanding of the nature of dropouts and identify those subsets of students that are at risk of leaving secondary education early. All four studies discovered remarkably consistent correlations (Table 3). Students who drop out tend to have four similar

19 As of $2011,54 \%$ of high school attendees go to academic high school, and $46 \%$ go onto vocational schools. See NBS 2014 . 
Table 3: Correlates of Dropout

\begin{tabular}{|c|c|c|c|}
\hline & $\begin{array}{l}\text { School level } \\
\text { surveyed }\end{array}$ & $\begin{array}{l}\text { Number of } \\
\text { observations }\end{array}$ & $\begin{array}{l}\text { Correlates: who is more likely to } \\
\text { drop out? }\end{array}$ \\
\hline Mo et al. 2013 & $\begin{array}{l}\text { Junior high } \\
\text { school }\end{array}$ & 1,507 & $\begin{array}{l}\text { Low academic performance, boys, } \\
\text { older, poverty }\end{array}$ \\
\hline Yi et al. 2012 & $\begin{array}{l}\text { Junior high } \\
\text { school }\end{array}$ & 7,811 & $\begin{array}{l}\text { Low academic performance, older, } \\
\text { poverty, has siblings, less educated } \\
\text { father, poor parental health, } \\
\text { migrated parent }\end{array}$ \\
\hline $\begin{array}{l}\text { Wang, Huan, } \\
\text { et al. 2014a }\end{array}$ & $\begin{array}{l}\text { Junior high } \\
\text { school }\end{array}$ & 4,840 & $\begin{array}{l}\text { Low academic performance, boys, } \\
\text { older, poverty, boarding status, has } \\
\text { siblings, less educated father, poor } \\
\text { mental health }\end{array}$ \\
\hline Yao et al. 2013 & $\begin{array}{l}\text { Vocational } \\
\text { high school }\end{array}$ & 7,172 & $\begin{array}{l}\text { Low academic performance, less } \\
\text { educated mother, migrated mother }\end{array}$ \\
\hline
\end{tabular}

characteristics: they tend to be boys, have lower academic achievement, be older and come from more disadvantaged family backgrounds (as revealed by their poverty status, number of siblings, parents' education, parents' migration status, etc.). These results are consistent with international findings. ${ }^{20}$

Huan Wang and colleagues conducted the only study to measure the correlation between dropping out of school and mental health, and also found that the student and family characteristics that correlate with dropping out of school also correlate with mental health issues. ${ }^{21}$ Even after controlling for student and family characteristics, mental health issues remain correlated with dropout rates.

\section{Qualitative Findings and Mixed-methods Analysis}

\section{Qualitative data collection}

As part of our effort to gain a better understanding of why students are dropping out, we conducted interviews with a randomly selected subset of students from two of our studies cited above. ${ }^{22}$ These interviews were conducted in two waves. All interviews took place in the autumn of what would be the students' first semester of senior high school. In each wave, we randomly selected 26 students to interview from our sample schools in Shaanxi province for a total of 52 interviews. As Table 4 shows, we interviewed 18 students who had already dropped out of school (dropouts), 11 students attending vocational high school (VHS), 20 students currently enrolled in academic high school (AHS) and 3 students repeating their final year of junior high school in order to retake the high school entrance exam (zhongkao 中考). All students were selected for 
Table 4: Interview Students' Characteristics (52 students)

Number of students

Grade level in $\mathbf{2 0 1 0}$

7 th grade

9th grade

Gender

Male

Female

Schooling choice

Dropped out

Repeating 9th grade

Attending vocational high school

Attending academic high school
26

26

26

26

18

3

11

20

participation in the study based on their being among the four poorest students in their class at the time of our initial survey in 2010. All interviews were conducted on a one-on-one basis, recorded, and transcribed. All 52 participants gave informed consent, and all personally identifiable information was removed from the transcripts. The interviews lasted from 30 to 90 minutes and were semistructured: interviewers referenced a scripted interview protocol but also had the freedom to diverge from this protocol in order to investigate specific stories that emerged.

\section{A Simple Framework for Understanding the Decision to Drop Out}

Based on both our quantitative data (above) and the qualitative findings presented below, we propose the following framework for understanding the decision to drop out. Students choose to drop out of the secondary education process according to two basic mechanisms. First, students may rationally consider the costs and benefits of staying in school and then conclude that they will likely be better off in the long run if they drop out. ${ }^{23}$ We will call this the "rational choice" mechanism. Alternatively, even if students have concluded that the long-term benefits of remaining in school outweigh the costs, they may face immediate psychological stressors that lead them to drop out of school impulsively in spite of their long-term prospects. ${ }^{24} \mathrm{We}$ shall refer to this as the "impulsive choice" mechanism. Both mechanisms are explained in more detail immediately below.

In the rest of the paper, we examine both the rational choice factors that are likely to influence students' decision making and the impulsive choice short-run stressors that may impel students to make sudden rash decisions to drop out of secondary education. 


\section{Rational choice: dropping out because the costs exceed the benefits}

Our rational choice mechanism relies on a framework we derive from Chengfang Liu et al. for explaining the rational decision of whether or not to participate in the secondary education system (in other words, whether or not to drop out). ${ }^{25}$ According to this framework, if rural students rationally consider the costs and benefits of staying in school, there are four general reasons why they would choose to drop out of the secondary education system.

First, it is possible that the cost of going to school (tuition + fees + opportunity cost), given the perceived benefit, is too high. Second, it is possible that students from poor families do perceive a high benefit to remaining in school but they face a binding liquidity constraint as a result of high levels of school tuition. Third, it is possible that the capabilities of students themselves are so low that they would not be able to meet the admission requirements for their desired level of schooling (for example, their high school entrance exam score would not be high enough for them to be admitted into academic high school), or that they would expect to derive very limited benefit from their continued efforts to learn. Finally, it could be that the quality of the school facilities, teachers and/or curriculum is so low that the students would have no incentive to attend; in other words, they would not expect to increase any human capital by staying in school (and, thus, the expected benefit would be low).

Both our quantitative data (above) and qualitative interviews (immediately below) suggest that each of these factors influences student dropout decisions to varying degrees during different windows of the secondary education process. In this section, we seek to show that rural students are rationally choosing to drop out from junior high and academic high school primarily owing to the interaction between the costs (including both the direct costs of school tuition and the opportunity costs represented by employment options outside of school) and their perceived capability (as measured by their academic performance). Vocational high school students, in turn, are likely to choose to drop out primarily because of school quality concerns that may be undermining the perceived returns to their education.

\section{Rational choice in junior high and academic high school: intertwining cost and capability concerns}

There is some evidence to suggest that rural students are dropping out owing to, at least in part, perceived direct and indirect costs to remaining in school. Our correlates' results, presented in Table 3, show that various metrics for "poverty" were significantly correlated with dropout in all reported studies. Studies conducted throughout the world and in China have long found that poverty correlates closely with low levels of educational attainment and high dropout 
rates. ${ }^{26}$ Poorer students are more likely to drop out in part because they are more profoundly affected by the costs of continuing their education. Indeed, the tuition fees for academic high school in China, which are the highest in the world, are known to impose a significant burden on many rural families. ${ }^{27}$

Whether seeking to attend academic or vocational school programmes, students face an additional cost: high and increasing opportunity costs to attending any kind of secondary school. According to Fang Cai and Yang Du, the unskilled wage rate in China has been rising since the early 2000s. ${ }^{28}$ Jikun Huang et al. show that, during the late 2000s, virtually all young, able-bodied rural individuals were able to find a job off the farm in China's coastal provinces. ${ }^{29}$ The same study also found that the monthly earnings of the typical unskilled worker (who had off-farm employment in both 2008 and 2009) were comparable to the annual per capita income in poor rural areas. Thus, by forgoing secondary school in order to enter the labour market, young rural Chinese can expect to make significant wages in the short term. While the longterm returns to these low-skill jobs are likely to be low, the short-term economic incentives rural students face may encourage them to drop out of education.

We found that dropping out was significantly correlated with both gender and age (as shown in Table 3, boys and older students are more likely to drop out), which we interpret as evidence of the importance of opportunity costs in influencing the decision to drop out. As older children are more likely to find a job that has a higher rate of pay, age can be a critical factor in opportunity cost-induced dropout. ${ }^{30}$ In China, boys may also be able to find higher wage employment more easily, given persistent gender disparities in pay rates for rural-urban migrants. We therefore suggest that higher opportunity costs may contribute to the decision to drop out.

A number of our in-the-field experiments conducted in rural China in the past few years have also demonstrated the importance of cost concerns in student dropout decision making. Studies have found that offering students tuition subsidies for remaining in junior high or matriculating into high school significantly boosts enrolment or lowers dropout rates. ${ }^{31}$ For example, Di Mo et al. found that offering cash incentives for staying in school reduced the dropout rate for rural junior high schools by around 60 per cent (from 13 per cent to 5 per cent).

Our interview results also support the finding that schooling costs are an important factor in shaping the decision to drop out of school. A large portion of the students we interviewed pointed to the direct costs of attending school as an important influencing factor in their decision-making process, as demonstrated by the following comments:

26 Ensminger and Slusarcick 1992.

27 Liu et al. 2009.

28 Cai and Du 2011.

29 Huang et al. 2011

30 Bhatty 1998; Charles and Luoh 2003

31 Mo et al. 2013. 
My parents had to work very hard to support my schooling. Since my grades were bad, going to school was just a waste of money. I figured that if I left school and got a job, even if I wasn't making much money, at least I would be able to support myself (Dropout, 332812132)

I didn't want to stay in school because I thought my family might not be able to support me. My mum said that I should go to high school even if it ended up being a waste of time. Then at least I could be better off. I said, "if I go to high school, will Dad be able to support me?" because there's no subsidy and you have to buy your own textbooks. I said, "if I stay in school after one year all our family's money will be used up." Then no one said anything else. And in the end I didn't go to high school. (Dropout, 3106346)

However, while the costs of schooling do play a crucial role in student decisions about whether to continue on to academic high school, our results suggest that costs alone cannot explain this decision. For example, while Di Mo et al. found that a scholarship agreement reduced dropout rates by 60 per cent, 40 per cent of the seventh graders receiving the scholarship in that programme still ended up dropping out during their grade seven year. ${ }^{33}$ Other programmes offering similar financial incentives for staying in school have been shown to have minimal effects on reducing dropout rates or increasing matriculation to high school. ${ }^{34}$

Our interviews also reflect this finding: while the direct and indirect costs of education play an important role in shaping students' thinking about dropping out of school, many students suggested that costs were not the principal or deciding factor. This was first evident in a number of students' assertions that their parents were committed to paying for their schooling, no matter the expense. Note that this suggests at least a share of students were not facing a binding liquidity constraint:

My parents were always very determined. No matter what I said, my mum would never agree to my dropping out. My dad also told me not to worry about the family. Just as long as I could get into high school, even if it meant more financial hardship, my family would still support me in my studies and with my tuition. (AHS, 3404621)

If I didn't get a scholarship - as long as I could get in - I still probably would have gone to high school. Because my mum told me, "My child, just as long as you can get into college, it doesn't matter what college. So long as you want to go, I will borrow money. I will borrow money for my whole life long and never recover if I can just help you get to college." (AHS, 1106546)

It is likely, then, that students' perceptions of the high costs of school, although significant, were weighed heavily against the perceived benefit. The perceived benefit of staying in junior high or academic high school seemed to hinge primarily on students' understanding of their academic capabilities. As Table 3 demonstrates, all of our studies found that dropping out was significantly correlated with poor academic performance. The international education literature has long shown that poor academic performance is one of the strongest and most consistent predictors of quitting education early - especially in competitive educational systems such as those in China. ${ }^{35}$

32 Each student in the sample was assigned a unique student ID number when the data was de-identified.

33 Ibid.

34 Yi et al. 2015; Li, Fan, et al. 2014.

35 Battin-Pearson et al. 2000; Cairns, Cairns and Neckerman 1989; Rumberger 1987. 
A number of students also stated explicitly that grades were a more important influencing factor than schooling costs. Many of the students interviewed had been offered a scholarship (through the intervention provided by the research team in the Hongmei Yi et al. (2015) study ${ }^{36}$ ) if they successfully matriculated into senior high school. However, students explained that the scholarship did not have a significant impact on their schooling choice simply because their grades were a far more critical factor. This is a particularly significant finding in light of the fact that all students interviewed in this study were among the poorest students in their counties; although they presumably had the most to gain from a scholarship programme, they still maintained that the scholarship's usefulness hinged on their academic capabilities.

When I got a scholarship it didn't change anything. I thought, I'm still not going to be able to [pass the] test into academic high school. No way. My grades were really bad. When my dad heard about the scholarship he said, "You still won't be able to get into academic high school." (Dropout, 1314308)

Even if I had received a full scholarship I think the likelihood of my going to high school would still have been low. My grades were bad so going to high school would still have been a waste of money. It would still be better to go get a job and make some money instead. (Dropout, 3106346)

Indeed, students from many backgrounds suggested that grades might well be one of the most important factors in determining their classmates' decisions to drop out.

That's how people decide whether or not to stay in school. Those who can learn, stay in school. Those that can't learn, drop out. (Dropout, 1314308)

Some of my friends dropped out of school and some are still in high school. It was pretty much decided by their grades. If their grades were bad, they left. Pretty much everyone who could [pass the] test for academic high school ended up going. (AHS, 1327232)

Moreover, nearly every dropout we spoke to emphasized that his or her grades were poor and cited that as a primary reason for dropping out. Some of these students dropped out before their grades became a true impediment to continuing on in school, while others were prevented outright from continuing on to academic high school because their score on the zhongkao was not high enough to be admitted.

\section{Rational choice in vocational schools: pervasive school quality concerns}

In the preceding section, we saw that many students are dropping out of junior high and academic high schools owing to the interaction between high costs and poor academic performance. By contrast, vocational high school is less expensive and less competitive, with more generous financial aid packages and minimal academic admission requirements. ${ }^{37}$ Therefore, vocational high school offers an alternative path for students who are excluded from academic high

37 Fo and Xing 2011; Yi et al. 2012. 
school to continue with their education. So, why are the students who are dropping out of junior high and not going to academic high school not enrolling at higher rates in vocational high schools? And why is it that almost one-third of vocational high school students are choosing to drop out, many after less than one year?

There is reason to believe that low costs and minimal academic requirements notwithstanding, the quality of vocational programmes is so low that students feel little incentive to enrol in or remain in vocational high schools. A number of recent studies have called into question the quality of vocational programmes. ${ }^{38}$ In particular, Prashant Loyalka et al. have shown that attending vocational high school actually leads to a deterioration in academic skills and does not improve career-specific skills. ${ }^{39}$ Indeed, our interviews suggest that rural children and their families widely perceive vocational high school education to be of a low standard. A number of students we interviewed stated that they would not consider going to these schools because they perceived them to be of such poor quality.

My grades in junior high were bad so I originally thought I might want to go to a vocational high school. But then my mum said there was no point in going to a vocational school. She'd heard from other people that it was useless so she didn't let me go. Then the tuition is also expensive. So I didn't go. (Dropout, 1325211)

I thought I might go to the local vocational school but I don't like that school. For lots of reasons. I think they would cheat me. Everyone says those schools are a scam. I wanted to go to academic high school, but my grades weren't good enough. I wish I could go now. (Dropout, 1305146)

In addition to the common perception from outside the school system that vocational high schools are of poor quality, many current students of those schools gave examples of the pervasive poor quality they encountered on a daily basis. This perceived poor school quality likely underlies the high vocational high school dropout rate (from 29 to 32 per cent across three years) reported in Table 2.

I'm not happy at this school. Our teachers aren't good, they're worse than my junior high teachers. They don't care. If you want to study, that's fine, but if you don't, they won't force you. And no one takes the academic classes seriously. The teachers don't even take a register in those classes. I don't even study for them. I only pay attention in my technical classes. (VHS, 1322104)

I really regret going to vocational school. It's like they're looking for ways to cheat us. And classes here are bad. The teacher's up there talking but no one understands anything. We all just sit there. A lot of people sleep through class. And, everyday, about half of the kids don't even come to class. Everyone regrets coming here. (VHS, 1103420)

From both the quantitative and qualitative findings, we believe that it is clear that the rational choice mechanism plays a key role in determining students' dropout decisions. In particular, the costs of schooling interact with students' perceived academic capabilities to incentivize dropping out of academic high school or 
prior to academic high school. At the same time, widespread school quality concerns are the primary factor motivating students' non-matriculation and dropout from vocational high schools.

Impulsive choice dropout: dropping out owing to short-term stressors and short-term benefits

While the rational choice mechanism laid out above likely explains a large part of student decision making, it may be that rational, long-term cost-benefit analysis alone cannot explain the high rates of dropping out of rural secondary schools. The field of behavioural economics studies the ways in which individuals of all ages sometimes make decisions that work against their true interests. Given mental development patterns in adolescence, secondary school-aged children may be even more likely to make impulsive decisions about such issues as dropping out of school. ${ }^{40}$ Other studies of secondary school dropout rates outside of the field of economics have also concluded that student dropout cannot be fully explained by rational cost-benefit analysis. ${ }^{41}$

Our findings suggest that rural students face short-term psychological stressors that may cause them to choose impulsively to drop out even when they know that they would be better off in the long run if they chose to stay in school. Primed by these stressors, students may also be spurred on to dropping out by the promise or perception (whether true or not) of a freer or easier life outside of school. If students are not carefully mentored by adults (parents or teachers) who care about their educational prospects, it is possible that students may make rash decisions that they will later come to regret.

The first evidence that students are making impulsive choices stems from their attitudes towards dropping out after they have made that decision. If students were accurately weighing the costs and benefits of dropping out of secondary education, it is unlikely - barring major changes in the costs and benefits of schooling - that they would come to regret their decision soon after. However, the majority of the dropouts we interviewed said that they regretted their choice or would make a different choice if they could go back in time. ${ }^{42}$ And, almost universally, the students stated that they would advise a current junior high school student to stay in school if at all possible.

From the first day I left school I immediately regretted it. I knew I would regret it from the beginning. But, even if I would regret it, I knew I had to leave, I had to get away from those girls. (Dropout, 1305335)

I have a friend who's still in junior high. He told me he was going to drop out and I asked him why. He said, "I want to go out on my own." I said, "What are you going to do?" He said, "The

40 Gruber 2001.

41 Oreopoulos 2003.

42 Although re-entering the schooling system after dropping out for a period of time is allowed in the Chinese system, it is very uncommon. When asked about this possibility, interviewed students responded that they would not seriously consider going back to school as they thought they were "too old" or it was "too late" for them. 
same as you." So, I told him to go back to school. He's only 17 . He should keep studying. (Dropout, 1302134)

Given that many students do not seem to be weighing up the costs and benefits of high school accurately, what could be contributing to their rash decision making? One obvious possibility is that students are simply poorly informed about the trade-offs between staying in school and dropping out. Indeed, one study found that students in poor, rural areas of China are misinformed about the returns of continuing on to senior high school. ${ }^{43}$ However, the same study also found that providing at-risk rural junior high school students with information about the secondary education process and its returns had no measurable effect on junior high school dropout rates.

Besides poor information, psychological stress in school may contribute to the short-term decision-making process of students. International research has shown that psychological factors, such as anxiety, depression, aggression and impulsiveness, are strong determinants of poor educational performance and dropout. ${ }^{44} \mathrm{~A}$ study conducted by Huan Wang et al. in rural Shaanxi province found that 74 per cent of surveyed seventh- and eighth-grade students were deemed clinically at risk for mental health issues, a rate 12 times higher than that found among urban students. ${ }^{45}$ This troubling statistic may be the result of more prevalent psychological stressors in the schooling and home environments of rural students. As shown in Table 3, the same study also found that poor mental health is significantly correlated with dropping out of school. We explore a number of psychological stressors that came up in our qualitative interviews as possible contributing factors to rural students' poor mental health and high dropout rates. We suggest that these psychological stressors may lead some students to start to disengage with school and consider dropping out.

Our interviews reveal that one major source of psychological stress in school stems from poor student-teacher relations. Many students blamed strained interactions with their teachers as the reason they disliked school or considered dropping out.

In class, the teacher would make you write English words up on the board and would hit whoever couldn't do it. I would get hit too. So, back then I didn't want to study English ... Back then, whenever I got yelled at, I just didn't want to stay in school. When I was in class, I just didn't want to listen. (Dropout, 3106347)

I left school halfway through the first year of junior high. I never liked school. I didn't like my teachers. There was one who I really hated ... She was too fierce. She would hit people. All the time. Whenever you made any kind of mistake ... Yeah, I was scared of her. We were all scared of her. (Dropout, 1302134)

In addition to strained relationships with their teachers, a number of students also pointed to poor relationships with their classmates as a significant short-run factor that caused them to consider dropping out. Indeed, a recent study conducted

45 Wang, Huan, et al. 2014a. 
in rural China found that fully 37 per cent of junior high school students reported being frequently bullied by their classmates. ${ }^{46}$

My relationships with my classmates were very bad. So that made me not like school. I can't tell you what they did. But it was so awful I just had to leave. (Dropout, 1305335)

There were a few kids with really bad grades who would bully other students on the street. They would make other kids buy things for them. And if you refused, they would beat you up. And if you accidentally bumped into one of them, then, after class, they would bring their friends and beat you up. I had three or four friends that were getting bullied. None of them dared to resist. If they resisted, they would just get beaten up even worse. The teachers didn't do anything to stop it. (Dropout, 3106347)

Primed to dislike school by the intertwining psychological stressors of poor grades and bad relationships with teachers and/or classmates, any kind of encouragement (or additional stress-filled event) to drop out of school may magnify the effect. Scholars have pointed out that dropping out of school is often the culmination of a gradual process of disengagement with school, at the end of which students are easily swayed by factors that can give them the final push or pull out of school. ${ }^{47}$ A number of students suggested that after considering it for a while, they finally decided to drop out only after hearing tales that life outside of school was better than life in school.

I started to hate school. Then I heard from other people about my age who were already working. That was when I started to think about dropping out to go work. I thought that getting a job might be more relaxed than staying in school. I first felt like I hated school, then I saw that other people had left to get jobs. I saw that after they came home from leaving to get jobs, they were all having fun and so happy. I started to think that maybe working would be less tiresome than school. Working would be more free. (Dropout, 3328121)

I wanted to go out and experience the real world ... That's what we would hear from other kids who had already dropped out. They said working was really great. When I told my mum, she yelled at me ... I just felt indifferent ... At that time, I was curious. (Dropout, 3305252)

Facing psychological stress in school and hearing about the freedom of life outside of school, a large proportion of rural students are also left with little positive guidance at home to help them determine the best course of action. In poor rural areas, there are many single-parent families or children who are "left-behind" by parents who have migrated to cities far away. Such children are often left to resolve the stressors of adolescence with little parental guidance. ${ }^{48}$ One study found that 18.1 per cent of junior high school students have had one or both of their parents migrate for work. ${ }^{49}$ Unfortunately, migrating parents are less able to care for or supervise their children's education, which in turn may increase students' chances of dropping out. In addition, migrating parents may serve as "role models," attracting children to migrate themselves and perhaps increasing the probability of finding a job. ${ }^{50}$ Indeed, as presented in Table 3, both Yi

46 Ibid.

47 Rumberger 1987.

48 Zhang, Gangying 2006.

49 Du, Park and Wang 2005.

50 Ibid. 
et al. (2012) and Yao et al. (2013) found that rural students are at higher risk of dropping out when their parents have migrated. Even for students who do have parents at home, a large proportion of students in rural China board at a school far from home and therefore have little interaction with their parents. ${ }^{51}$ Huan Wang et al. (2014a) showed that dropping out of junior high school is correlated with being a boarding student (Table 3 ).

Many interviewed students spoke of the limited guidance they received from distant parents.

My dad really cares about my studies ... My dad would always ask me about my situation at school, but I didn't like to talk to them about it. I was always confused in class so if I told them that it would just make them sad. Before, when I would go home, my dad would always supervise me doing my homework. But then after he migrated to work far away, I pretty much never did any homework. (Dropout, 3510301)

I never really talked with my dad very much. My mum would sometimes tell me that I should study hard. But I really didn't interact with either of them very much. I would go home from school on Friday and then I'd have to go back to school by Sunday afternoon. Then, sometimes when I was home, everyone was busy so I would have to help them do chores. Or sometimes my parents weren't home. So, we really didn't talk that much. (Dropout, 1325211)

Research in developed countries suggests that a mentor can play a key role in averting dropout. ${ }^{52}$ Without their parents playing this role, many of these students were left to decide for themselves, based on short-run considerations and imperfect information, whether to continue with school or drop out. ${ }^{53}$

In this section, we have brought together results from our quantitative and qualitative findings to show that while some students rationally considered the long-term costs and benefits of remaining in school and ended up deciding to drop out, many rural secondary students were also led to drop out by mechanisms they later came to regret. Under psychological pressure both in and out of school, these students came to believe that school was a painful place they wanted to escape however they could. Informed by others about the "freedom" of the wider world - and with little guidance from parents or teachers - many of them impulsively chose to drop out and try their luck.

\section{Conclusions}

In this paper, we bring together, for the first time, results from eight survey studies conducted across rural China in the past seven years. We show that dropout rates are high across the secondary education process. Between 17.6 per cent and 31 per cent of rural students are not finishing junior high school. Including these early dropouts, less than half of rural students are matriculating into either academic or vocational high schools. Dropout rates from academic and vocational high school are also troublingly high. All told, our findings suggest that the

53 Yi et al. (2012) also show that dropout is significantly correlated with poor parent health. Poor health may be another driver of emotional distance between parents and at-risk children. 
cumulative dropout rate across all windows of secondary education may be as high as 63 per cent. That is, if 100 students enter junior high, only 37 of them will graduate from either a vocational or academic high school.

Based on a rich set of interviews with students, we suggest that two different mechanisms are driving students to drop out of secondary education in rural areas. First, some students appear to be making a rational choice to drop out based on (a) high costs, (b) high academic requirements, and (c) poor school quality. Second, even students who conclude that the long-term benefits of further schooling exceed the costs are dropping out. In this paper, we suggest that these students may be making an impulsive choice to drop out of school based on the psychological stressors they face in the classroom, the tales they hear from friends about the short-term benefits of leaving school, and limited parental and teacher guidance to encourage them to stay in school.

Three recommendations can be derived from these findings. Our results suggest that there are two major barriers to increasing enrolment into academic high school. First, high tuition rates for academic high school - especially in light of rising opportunity costs - create a backdrop against which dropping out of school is a much more appealing option. This suggests that lower tuition rates (or more accessible financial aid) would greatly increase enrolment. Second, and perhaps even more significantly, the rigorous academic requirements for admission to academic high school (and the strict limits on enrolment) pose a serious barrier to academic high school matriculation in rural China today. We recommend that China follow most other developed nations in making education compulsory and free all the way through to the end of senior high school.

In addition, enrolment and completion in vocational high schools are unlikely to rise unless the quality of these schools can be improved. Furthermore, all students will likely require general academic skills (for example, in subjects such as mathematics, reading and science), if they wish to compete in higher-wage labour markets in China's future economy. This suggests that Chinese education policymakers interested in continuing or expanding current vocational programmes should place the highest priority on improving the quality of both vocational (technical) and academic (general) training in all schools.

Finally, our results suggest that even if the long-term benefits of remaining in school can truly be made to exceed the costs, high dropout rates might still persist. We find that rural students face a range of psychological stressors that may spur them to drop out. International research has shown that many of the most successful interventions in preventing students from dropping out of secondary education rely on increased mentoring and monitoring of at-risk students. ${ }^{54}$ Preliminary results from a study conducted in rural China suggest that providing rural students with "life counsellors," who teach a weekly class on handling mental health stress and make themselves available as mentors to their students, 
significantly reduces dropout rates at the junior high level. ${ }^{55}$ More programmes to provide poor rural students with this sort of mentoring are needed.

\begin{abstract}
摘要：中国农村地区的中学生辍学率正处在一个令人不安的高度。尽管大 量的定量研究关注过这一议题，但还没有研究利用混合方法系统地分析学 生选择辍学的深层次原因。本文旨在探索农村中学阶段学生辍学现状、相 关因素以及潜在的原因。为此，基于八次大规模调研收集的来自四个省 24931 名农村中学生的数据, 以及与 52 名来 自样本地区的农村学生的深入 访谈, 我们发现, 农村地区整个中学阶段的累计辍学率高达 $63 \%$ 。而辍学与 学习成绩差、机会成本高、社会经济地位低，以及心理健康问题有着显著 的相关性。分析结果显示, 农村地区中学阶段的辍学主要是受两种机制的 影响: 理性的成本一收益分析, 和一时冲动的压力胁迫下的决策。
\end{abstract}

关键词: 辍学; 中国; 中等教育; 相关因素; 定性研究; 混合方法分析

\title{
References
}

Barro, Robert J. 1991. "Economic growth in a cross section of countries." The Quarterly Journal of Economics 106(2), 407-443.

Battin-Pearson, Sara, Michael D. Newcomb, Robert D. Abbott, Karl G. Hill, Richard F. Catalano and J. David Hawkins. 2000. "Predictors of early high school dropout: a test of five theories." Journal of Educational Psychology 92(3), 568-582.

Bhatty, Kiran. 1998. "Educational deprivation in India: a survey of field investigations." Economic and Political Weekly 33(27), 1731-40.

Birdsall, Nancy, David Ross and Richard Sabot. 1995. "Inequality and growth reconsidered: lessons from East Asia." The World Bank Economic Review 9(3), 477-508.

Cai, Fang, and Yang Du. 2011. "Wage increases, wage convergence, and the Lewis Turning Point in China." China Economic Review 22, 601-610.

Cairns, Robert B., Beverley D. Cairns and Holly J. Neckerman. 1989. "Early school dropout: configurations and determinants." Child Development 60(6), 1437-52.

Charles, Kerwin Kofi, and Ming-Ching Luoh. 2003. "Gender differences in completed schooling." Review of Economics and Statistics 85(3), 559-577.

Clarke, Marguerite, Walter Haney and George Madaus. 2000. "High stakes testing and high school completion." National Board on Educational Testing and Public Policy 1(3), 1-13.

Deng, Wengen, Liangxin Lei and Banhao Cao. 2002. "A survey on mental health of urban middleschool students in Jiangxi province." Health Psychology Journal 10(4), 292-93.

Du, Yang, Albert Park and Sangui Wang. 2005. "Migration and rural poverty in China." Journal of Comparative Economics 33(4), 688-709.

Eckstein, Zvi, and Kenneth I. Wolpin. 1999. "Why youths drop out of high school: the impact of preferences, opportunities, and abilities.” Econometrica 67(6), 1295-1339.

Ensminger, Margaret E., and Anita L. Slusarcick. 1992. "Paths to high school graduation or dropout: a longitudinal study of a first-grade cohort." Sociology of Education 65(2), 95-113.

Fo, Zhaohui, and Hui Xing. 2011. "Survey on the implementation of the national stipend policy in secondary vocational schools." The China Educational Development Yearbook 3, 153-168.

55 Wang, Huan, et al. 2014b. 
Gruber, Jonathan. 2001. Risky Behavior among Youths: An Economic Analysis. Chicago: University of Chicago Press.

Heckman, James J., and Junjian Yi. 2012. "Human capital, economic growth, and inequality in China." NBER Working Paper No. 18100.

Huang, Jikun, Huayong Zhi, Zhurong Huang, Scott Rozelle and John Giles. 2011. "The impact of the global financial crisis on off-farm employment and earning in rural China." World Development 39 (5), 797-807.

International Labor Organization. 2010. "Mexico: rising unemployment, higher informal sector employment and reduced hours of work." Geneva: ILO Department of Statistics.

Johnson, R. Burke, and Anthony J. Onwuegbuzie. 2004. "Mixed methods research: a research paradigm whose time has come." Educational Researcher 33(7), 14-26.

Kokko, Katja, Richard E. Tremblay, Eric Lacourse, Daniel S. Nagin and Frank Vitaro. 2006. "Trajectories of prosocial behavior and physical aggression in middle childhood: links to adolescent school dropout and physical violence." Journal of Research on Adolescence 16(3), 403-428.

Kuczera, Małgorzata, and Simon Field. 2012. "Learning for jobs: OECD reviews of vocational education and training: options for China," http://www.oecd.org/china/45486493.pdf. Accessed 24 September 2015.

Li, Fan, Prashant Loyalka, Chengfang Liu, Hongmei Yi, Linxiu Zhang, James Chu, Natalie Johnson and Scott Rozelle. 2014. "The impact of conditional cash transfers on the matriculation of junior high school students into rural China's high schools.” REAP Working Paper No. 282, Stanford University.

Liu, Chengfang, Linxiu Zhang, Renfu Luo, Scott Rozelle, Brian Sharbono and Yaojiang Shi. 2009. "Development challenges, tuition barriers, and high school education in China." Asia Pacific Journal of Education 29, 503-520.

Liu, Chengfang, Linxiu Zhang, Renfu Luo, Hongmei Yi, Jikun Huang and Yaojiang Shi. 2012. "Puji pinkun diqu nongcun gaozhong jieduan jiaoyu de tansuo he zhengce jianyi" (Suggestions for making high school level education universal in poor rural areas). Policy brief, Center for Chinese Agricultural Policy, Chinese Academy of Sciences, Beijing.

Loyalka, Prashant, Chengfang Liu, Yingquan Song, Hongmei Yi, Xiaoting Huang, Jianguo Wei, Linxiu Zhang, Yaojiang Shi, James Chu and Scott Rozelle. 2013a. "Can information and counseling help students from poor rural areas go to high school? Evidence from China." Journal of Comparative Economics 41(4), 1012-25.

Loyalka, Prashant, Xiaoting Huang, Linxiu Zhang, Jianguo Wei, Hongmei Yi, Yingquan Song, Baoping Ren et al. 2013b. "The impact of vocational schooling on human capital development in developing countries: evidence from China." REAP Working Paper No. 265, Stanford University.

Loyalka, Prashant, James Chu, Joel Reniker, Natalie Johnson and Scott Rozelle. 2014. "Inequality in the pathway to college in China." REAP Working Paper No. 277, Stanford University.

Ministry of Education. 2006. "Statistical communiqué on national educational development in 2005," http://www.moe.edu.cn/moe_2792/moe_2863/moe_2832/201002/t20100209_49957.htm. Accessed 24 September 2015.

Mo, Di, Linxiu Zhang, Hongmei Yi, Renfu Luo, Scott Rozelle and Carl Brinton. 2013. "School dropouts and conditional cash transfers: evidence from a randomised controlled trial in rural China's junior high schools." The Journal of Development Studies 49(2), 190-207.

NBS (National Bureau of Statistics). 2007. China Statistical Yearbook. Beijing: China Statistics Press.

NBS. 2012. China Statistical Yearbook. Beijing: China Statistics Press.

NBS. 2014. China Statistical Yearbook. Beijing: China Statistics Press.

Oreopoulos, Philip. 2003. "Do dropouts drop out too soon? Evidence from changes in school-leaving laws." NBER Working Paper No. 10155.

Rumberger, Russell W. 1987. "High school dropouts: a review of issues and evidence." Review of Educational Research 57(2), 101-121. 
Tyler, John H., and Magnus Lofstrom. 2009. "Finishing high school: alternative pathways and dropout recovery." The Future of Children 19(1), 77-103.

Wang, Huan, Chu Yang, Fei He, Yaojiang Shi, Qinghe Qu, Scott Rozelle and James Chu. 2014a. "Mental health and dropout behavior: a cross-sectional study of junior high students in northwest rural China." International Journal of Educational Development 41, 1-12.

Wang, Huan, James Chu, Prashant Loyalka, Xin Tao, Yaojiang Shi, Qinghe Qu, Chu Yang and Scott Rozelle. 2014b. "Can school counseling reduce school dropout in developing countries?" REAP Working Paper No. 275.

Wang, Xiaobing, Chengfang Liu, Linxiu Zhang, Renfu Luo, Thomas Glauben, Yaojiang Shi, Scott Rozelle and Brian Sharbono. 2011. "What is keeping the poor out of college? Enrollment rates, educational barriers and college matriculation in China." China Agricultural Economic Review 3(2), 131-149.

World Bank. 2005. World Development Report 2006: Equity and Development. Washington, DC: World Bank and Oxford University Press.

Yao, Joe, Hongmei Yi, Linxiu Zhang, Huan Wang, Chu Yang, Yaojiang Shi, James Chu, Prashant Loyalka and Scott Rozelle. 2013. "Exploring dropout rates and causes of dropout in upper-secondary vocational schools." REAP Working Paper No. 261.

Yi, Hongmei, Yingquan Song, Chengfang Liu, Xiaoting Huang, Linxiu Zhang, Yunli Bai, Yaojiang Shi et al. 2015. "Giving kids a head start: the impact of early commitment of financial aid on poor seventh grade students in rural China." Journal of Development Economics 113, 1-15.

Yi, Hongmei, Linxiu Zhang, Renfu Luo, Yaojiang Shi, Di Mo, Xinxin Chen, Carl Brinton and Scott Rozelle. 2012. "Dropping out: why are students leaving junior high in China's poor rural areas?" International Journal of Educational Development 32(4), 555-563.

Zhang, Gangying. 2006. "Nongcun zhongxuesheng xinli jiankang zhuangkuang de diaocha yanjiu" (A survey on mental health of rural middle-school students). Xinli yu xingwei yanjiu 4(3), 180-83.

Zhang, Linxiu, Hongmei Yi, Renfu Luo, Changfang Liu and Scott Rozelle. 2012. "The human capital roots of the middle income trap: the case of China." Paper presented at the 28th Triennial Conference of the IAAE, Foz do Iguaçu, Brazil, 18-24 August 2012. 